\title{
DEVELOPMENT OF AN ANALYTICAL SOLUTION MATHEMATICAL MODEL FOR A THERMOPLASTIC STARCH AND LINEAR LOW-DENSITY POLYETHYLENE BLENDS FOR PYROLYTIC DEGRADATION
}

\author{
SULTAN M. AL-SALEM ${ }^{1}$, ALI BUMIJDAD ${ }^{2}$, ABDULREHMAN KHAN $^{1}$ \& FAJER A. AL-TURKI FI $^{3,4}$ \\ ${ }^{1}$ Environment \& Life Sciences Research Centre, Kuwait Institute for Scientific Research, Kuwait \\ ${ }^{2}$ Chemistry Department, Faculty of Science, Kuwait University, Kuwait \\ ${ }^{3}$ Environmental Sciences Joint Program, College of Graduate Studies, Kuwait University, Kuwait \\ ${ }^{4}$ Enviormental Program, Kuwait Foundation for the Advancement of Sciences, Kuwait
}

\begin{abstract}
The increase in the use of polymeric articles has led to the accumulation of large amounts of plastic solid waste (PSW) over recent decades. Proper methods must be implemented to treat PSW, such as the process of thermal degradation, leading to the recovery of highly desirable chemicals. Attention has shifted to biodegradable materials, due to their effectiveness in reducing waste and their role as a technology competing with conventional recycling methods. However, this will also result in an accumulation of such materials in the PSW stream, which can be further treated by chemical or thermal means. In this work, low density polyethylene (LLDPE) blends were compounded using $20 \mathrm{wt} \%$ and 40 wt. $\%$ of Poly Starch None (PSN), with the aim of examining their degradation kinetics. An analytical solution was also developed for evaluating the kinetic parameters of the thermal degradation reaction of the linear low density polyethylene (LLDPE) and PSN blends. The main objective of this work was to study the degradation kinetics of starch based biodegradable polymers and, by so doing, to make available to consumers a solution to the accumulation of PSW in Kuwait, without affecting the environment. The average apparent activation energy $\left(\mathrm{E}_{\mathrm{a}}\right)$ calculated was determined to be 150 and 200 $\mathrm{kJ} \mathrm{mol}^{-1}$ for the $20 \mathrm{wt} . \%$ and $40 \mathrm{wt} . \%$ blends, respectively, which was within the acceptable ranges for degradation kinetics.
\end{abstract}

Keywords: starch, kinetics, degradation, polymeric blends, apparent activation energy (Ea).

\section{INTRODUCTION}

Plastics are comprised of polymers and additives, whether virgin or originating from various types of solid waste (SW). Therefore, understanding a polymer's structure, origin, and response under certain operating conditions is an essential step in assessing its behaviour under thermal treatment conditions. It is also imperative to predict and determine the proper measures in thermal units' design and operation, when industrial scale-up is desired. Investigating and inspecting polymers' behaviour under certain thermal conditions is likewise of importance.

It is well established that the dependency on polyolefin (PO) polymers has increased, due to their mechanical and physical properties after conversion into plastic articles. However, this increases the accumulation of plastic solid waste (PSW) and the associated environmental stressors. A technology in competition with recycling is biodegradable plastic conversion and manufacturing, where microorganisms attack polymeric chains, promoting early degradation to the backbone structure of the material. The most common type of PO is polyethylene (PE), which comes in three major types: high (HDPE), low (LDPE) and linear low density (LLDPE). The degradation of PE can be aided by the addition of carbonyl groups within its backbone or in situ generation of the carbonyl groups by pro-oxidants [1]. These pro-oxidant chemicals include various additives, e.g. polyunsaturated compounds, transition 
metal ions and metal complexes, which render polyethylene susceptible to hydro-per-oxidation [2]. Alternatively, light transforming additives (LT) and/or Ultraviolet (UV)-stabilizers are added to reverse the process and stabilize the polymer to make it more light resistant [3]. On the other hand, incorporating starch into the polymer's backbone structure promotes bacteria attack in a biodegradation process [4]. Various researchers have reported starch-filled PE properties post weathering [5]-[6], and there have also been other degradation media studies [7]-[9]. Research into biodegradable polymers has always lacked one important aspect, showing a clear gap in the research. This gap is the fate of biodegradable blends post thermal and thermo-chemical treatment (TCT). This type of work can give way to a future scale-up for unit operation, which can treat such an accumulation of material if it were to end up in a SW stream. In this work, TCT is mimicked in micro scale by performing pyrolytic runs on biodegradable plastic materials. The kinetics of thermal degradation were estimated to study the behaviour of these materials. To the best of the authors' knowledge, no such work has been attempted in the past.

\section{EXPERIMENTAL}

\subsection{Materials}

Virgin linear low-density polyethylene (vLLDPE), film extrusion grade, donated by a local supplier in pellet form $(3 \mathrm{~mm})$ with a melting point $\left(\mathrm{T}_{\mathrm{m}}\right)$ of $124^{\circ} \mathrm{C}$, melt flow index (MFI) of $2 \mathrm{~g} / 10 \mathrm{~min}$ and a density $\left(0.918 \mathrm{~g} \mathrm{~cm}^{-3}\right)$, was used. Flakes of Polystarch-N (PSN) were purchased from Willow Ridge Plastics (USA) with masterbatch properties as follows: $\mathrm{T}_{\mathrm{m}}$ $\left(110^{\circ} \mathrm{C}\right)$, MFI $(10 \mathrm{~g} / 10 \mathrm{~min})$ and density $\left(1.17 \mathrm{~g} \mathrm{~cm}^{-3}\right)$. The PSN-N used was a blend of $55 \%$ corn starch master batch and 45\% LLDPE. The corn starch master batch includes processing aids and a desiccant, the exact proportions of which are not revealed by the manufacturers, MSDS.

\subsection{LLDPE/PSN compounding}

A Collin Tech single-screw extruder $(\mathrm{D}=26 \mathrm{~mm}, \mathrm{~L} / \mathrm{D}=32)$ was used for compounding the samples. The LLDPE/PSN dry blends were processed under a 30-bar operating pressure with a rotational speed of $800 \mathrm{rpm}$. Zone temperatures were maintained at between $155-165^{\circ} \mathrm{C}$, with a die heat temperature (DHT) of $165^{\circ} \mathrm{C}$. Two dry blends were prepared, containing $20 \%$ and $40 \%$, respectively, by weight of PSN. Extruded strands were pelletized using a Collin Tech Line (CSG 171T) pelletizer to $3 \mathrm{~mm}$ pellets for further testing.

\subsection{Thermogravimetric analysis (TGA)}

Thermogravimetry in non-isothermal (dynamic) setup was performed for the LLDPE and LLDPE/PSN blends in a Shimazdu DTG-60, coupled with data acquisition software (TA analysis 1.51), in which weight loss and weight derivative against temperature curves were recorded. Samples were heated from room temperature $\left(25^{\circ} \mathrm{C}\right)$ to $800^{\circ} \mathrm{C}$. Five heating rates $(\beta)$ were used in conducting the experiments, as follows: $5,10,15,20$ and $25^{\circ} \mathrm{C} \mathrm{min}{ }^{-1}$.

A constant flow of dry nitrogen with a flow rate of $50 \mathrm{ml} / \mathrm{min}$ was maintained throughout, using 7-8 mg samples. Duplicate experiments were performed showing high repeatability within an error of $\pm 5 \%$. 


\subsection{Development of the analytical solution mathematical model}

In this work, an analytical solution was developed for evaluating the kinetic parameters of the thermal degradation reaction of the LLDPE and PSN blends. Rearranging the decay expression of kinetics, previously explained in Al-Salem and Khan [10], results in the following expression for a known reaction time $(\mathrm{t}, \mathrm{min})$ :

$$
\frac{d x_{P}}{x_{p}^{n}}=-k d t
$$

The degradation reaction is assumed to be of $n^{\text {th }}$ order, and both sides of eqn (1) were integrated for time equals to zero (i.e. for a polymer fraction equal to 1 ) to time equals to $(t)$, assumed to be the end of the experimental run (pyrolysis reaction), as the real integral limits result in the following expression:

$$
\frac{x^{-n+1}}{-n+1}=-k t
$$

Substituting $\mathrm{k}$ with the Arrhenius expression shown in eqn (2) and rearranging the denominator results in eqn (3):

$$
x=((n-1) A \exp (-E / R T) t+1)^{(-1 /(n-1))}
$$

In mathematical terms, the optimization problem is posed as follows:

$$
\text { Objective Function (O.F.) }=\min \sum_{\mathrm{i}=1}^{\mathrm{N}}\left|\frac{\mathrm{x}_{\mathrm{P}_{(\exp )}}-\mathrm{x}_{\left.\mathrm{p}_{(\text {(t) }}\right)}}{\mathrm{x}_{\mathrm{p}_{(\mathrm{exp})}}}\right| \text {, }
$$

where $\mathrm{N}$ is the number of time steps for the model solution.

The O.F. is the summation of the expression in eqn (4), where $x_{p(\exp )}$ and $x_{p(\mathrm{th})}$ are the experimental values and model values corresponding to the solution at each given time, subject to the following constraints:

$$
\begin{gathered}
E_{a} \geq 0 \\
t_{o}=0 \\
x_{p}\left(t_{o}\right)=1
\end{gathered}
$$

The objective function has three variables: the pre-exponential factor $\left(\mathrm{A}_{\mathrm{o}}\right)$, apparent energy of activation $\left(\mathrm{E}_{\mathrm{a}}\right)$ and reaction order $(n)$, which are optimized to match experimental weight fractions as a function of time and temperature, based on a pre-set constant heating rate $(\beta)$ with model computed values. Multi-variable non-linear optimization was used to solve the problem.

\section{RESULTS AND DISCUSSION}

The apparent activation energies $\left(E_{a}\right)$ and pre-exponential factors $\left(A_{o}\right)$ were calculated by using the solver function in Microsoft's Excel program, and the reaction order, n, was estimated to be 1 for LLDPE and between 1 and 2 for both blends, respectively. For LLDPE, the activation energies for the five different heating rates from 5 to 25 are as follows: 232, 212, 213, 203 and $190 \mathrm{~kJ} / \mathrm{mol}$; the temperatures of degradation of the LLDPE are 386, 405, 408,410 and $415^{\circ} \mathrm{C}$, respectively, as shown in Fig. 1. Fig. 1 also shows the experimental vs. 
the theoretical values for LLDPE, and it was observed that the experimental data fit the model very well, which shows in the regression coefficient $\left(r^{2}\right)$ values in Table 1.

A common trend was observed, with higher heating rates $(\beta)$ resulting in lower apparent activation energies ( $\left.E_{a}\right)$ for LLDPE. This was expected, since higher $\beta$ will result in more rapid degradation of the polymer's chain. From the regression coefficients $\left(r^{2}\right)$ for all heating rates, it was also observed that the theoretical data were in close proximity to the experimental data points. The energy of activation for PSN $20 \%$ and $40 \%$ is less than for the virgin LLDPE. This is due to the effect of starch content in the blend. It was observed that the same activation energy results were calculated for both blends for all heating rates. This indicates that a plateau is reached with starch content, such that no effect is observed after any addition of the material in the blend.

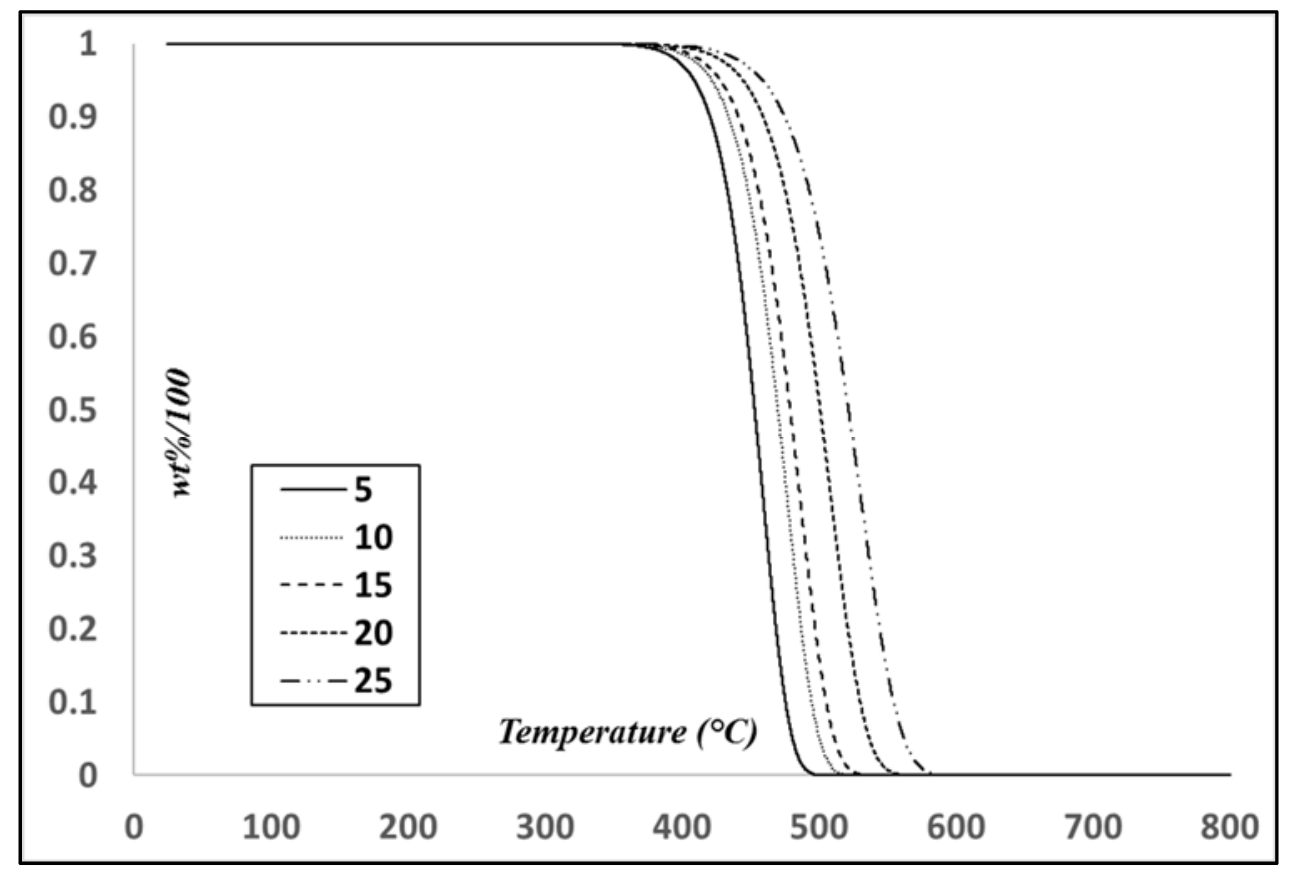

Figure 1: Model vs. experimental results for LLDPE.

Table 1: Average (apparent activation energy, $\left.\mathrm{E}_{\mathrm{a}}\right)$ for LLDPE, pre-exponential factor $\left(\mathrm{A}_{\mathrm{o}}\right)$ and regression coefficient $\left(r^{2}\right)$ between experimental and theoretical fits for all heating rates.

\begin{tabular}{c|c|c|c}
\hline Heating rate $\left(\beta,{ }^{\circ} \mathrm{C} \mathrm{min}^{-1}\right)$ & $\mathrm{E}_{\mathrm{a}}\left(\mathrm{kJ} \mathrm{mol}^{-1}\right)$ & $\mathrm{A}_{\mathrm{o}}\left(\mathrm{min}^{-1}\right)$ & $r^{2}$ \\
\hline 5 & 232.440 & $6.97 \times 10^{12}$ & 0.999 \\
10 & 221.133 & $9.02 \times 10^{11}$ & 0.998 \\
15 & 213.109 & $2.41 \times 10^{11}$ & 0.999 \\
20 & 202.986 & $2.43 \times 10^{10}$ & 0.997 \\
25 & 189.824 & $1.76 \times 10^{9}$ & 0.992 \\
\hline
\end{tabular}


The analytical solution gave a two-step $E_{a}$ for both degradation steps (Fig. 2), with a value of 150 and $200 \mathrm{~kJ} \mathrm{~mol}^{-1}$, respectively. The results of the model gave a high fit with the experimental values. Experimentally, the initial degradation of the blends showed water evaporation from the amount of water absorbed by the starch in the surrounding air.

Fig. 2 and Fig. 3 depict the experimental data for the blends investigated for all successive rates and also show the model results. It was observed that, with the increase of the PSN fraction in blends, the thermogravimetric (TG) curve showed a shift to lower value in the degradation temperature (i.e. onset temperature). The pure LLDPE, 20/80 and (wt.\% PSN/wt.\% LLDPE) blends start decomposing at temperatures of about $415^{\circ} \mathrm{C}$ and $291{ }^{\circ} \mathrm{C}$, respectively. The experimental results also depicted the loss of moisture clearly in the first stages, due to water absorption from the atmosphere by the starch content in the polymeric blend.

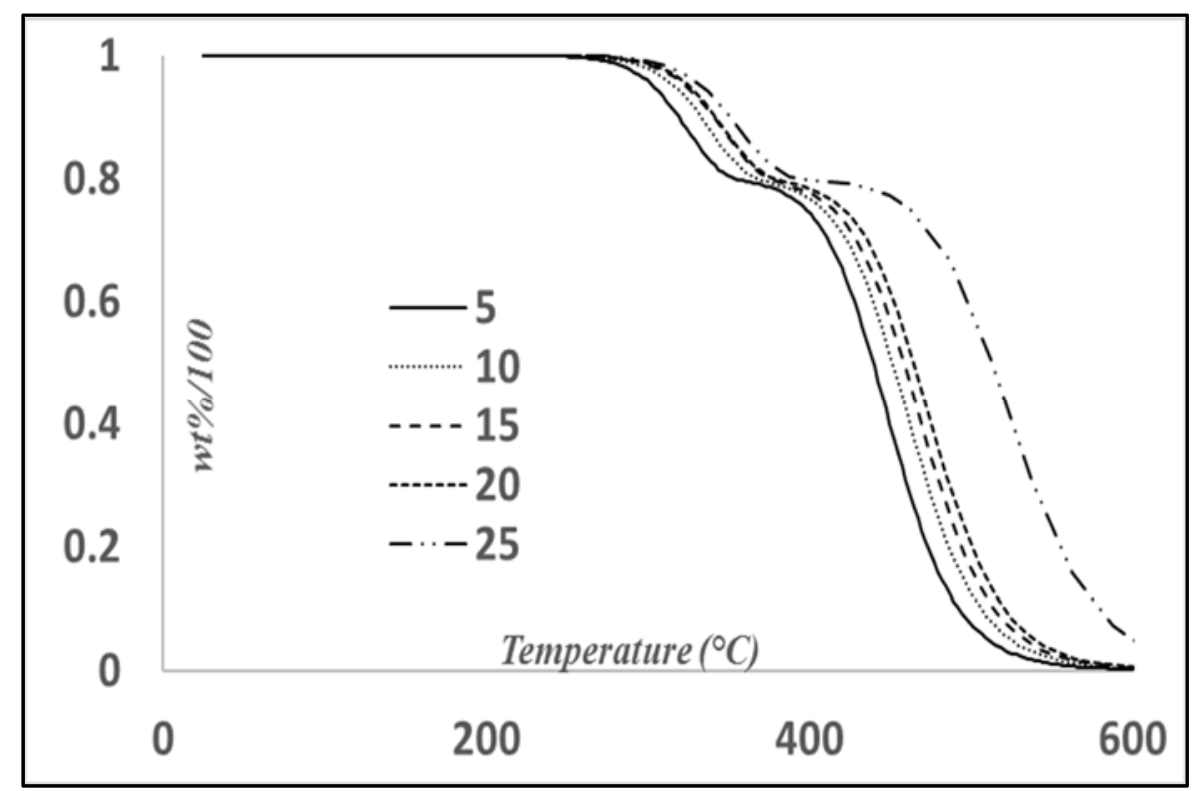

Figure 2: Model vs. experimental results for PSN-20\%.

Table 2: Average apparent activation energy $\left(E_{a 1}, E_{a 2}\right)$ for PSN 20 blend, showing the preexponential factor $\left(A_{1}, A_{2}\right)$ and regression coefficient $\left(r^{2}\right)$ between experimental and theoretical fits for all heating rates.

\begin{tabular}{|c|c|c|c|c|c|}
\hline $\begin{array}{l}\text { Heating rate } \\
\left(\beta,{ }^{\circ} \mathrm{C} \min ^{-1}\right)\end{array}$ & $\mathrm{Ea}\left(\mathrm{kJ} \mathrm{mol}^{-1}\right)$ & $\mathrm{E}_{\mathrm{a} 2}\left(\mathrm{~kJ} \mathrm{~mol}^{-1}\right)$ & $\mathrm{A}_{1}\left(\mathrm{~min}^{-1}\right)$ & $\mathrm{A}_{2}\left(\mathrm{~min}^{-1}\right)$ & $r^{2}$ \\
\hline 5 & 150 & 200 & $1.96 \times 10^{11}$ & $3.27 \times 10^{12}$ & 0.999 \\
\hline 10 & 150 & 200 & $1.91 \times 10^{11}$ & $3.72 \times 10^{12}$ & 0.998 \\
\hline 15 & 150 & 200 & $1.89 \times 10^{11}$ & $4.01 \times 10^{12}$ & 0.998 \\
\hline 20 & 150 & 200 & $4.58 \times 10^{11}$ & $8.21 \times 10^{12}$ & 0.998 \\
\hline 25 & 150 & 200 & $1.93 \times 10^{11}$ & $6.04 \times 10^{11}$ & 0.992 \\
\hline
\end{tabular}


Table 3: Average apparent activation energy $\left(E_{a 1}, E_{a 2}\right)$ for PSN 40 blend, showing the preexponential factor $\left(A_{1}, A_{2}\right)$ and regression coefficient $\left(r^{2}\right)$ between experimental and theoretical fits for all heating rates.

\begin{tabular}{c|c|c|c|c|c}
\hline $\begin{array}{c}\text { Heating rate }(\beta, \\
\left.{ }^{\circ} \mathrm{C} \mathrm{min}{ }^{-1}\right)\end{array}$ & $\mathrm{E}_{\mathrm{a} 1}\left(\mathrm{~kJ} \mathrm{~mol}^{-1}\right)$ & $\mathrm{E}_{\mathrm{a} 2}\left(\mathrm{~kJ} \mathrm{~mol}^{-1}\right)$ & $\mathrm{A}_{1}\left(\mathrm{~min}^{-1}\right)$ & $\mathrm{A}_{2}\left(\mathrm{~min}^{-1}\right)$ & $r^{2}$ \\
\hline 5 & 150 & 200 & $2.10 \times 10^{11}$ & $2.57 \times 10^{12}$ & 0.999 \\
10 & 150 & 200 & $1.73 \times 10^{11}$ & $3.33 \times 10^{12}$ & 0.999 \\
15 & 150 & 200 & $3.51 \times 10^{10}$ & $5.82 \times 10^{12}$ & 0.998 \\
20 & 150 & 200 & $5.04 \times 10^{10}$ & $1.91 \times 10^{12}$ & 0.998 \\
25 & 150 & 200 & $2.21 \times 10^{10}$ & $9.36 \times 10^{10}$ & 0.996 \\
\hline
\end{tabular}

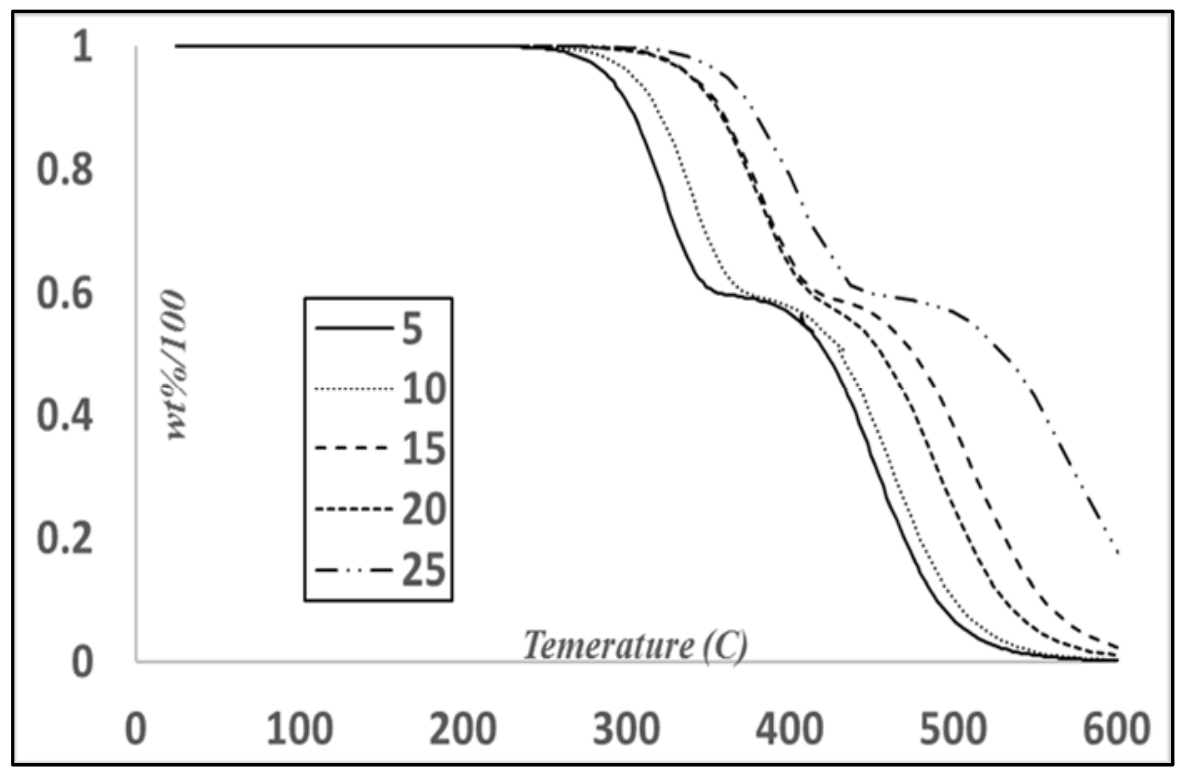

Figure 3: Model vs experimental results for PSN-40\%.

\section{CONCLUSION}

A general mathematical expression, based on the integral solution, was developed by utilizing thermogravimetric analysis (TGA) results in an inert atmosphere for biodegradable polymer blends and these were also compared to a commercial grade virgin LLDPE. The experimental data fitted the model to a high degree, depicting the true pyrolytic reaction behaviour. This clearly indicates the degradation mechanism, as the two stages of decay are shown. As the heating rate increased, the activation energy decreased, reflecting the progression of the reaction. LLDPE activation energy $\left(E_{a}\right)$ was higher than the PSN blends using all heating rates. The degradation of the PSN blends started at lower temperatures than the blends with a higher fraction of LLDPE, i.e. $40 \mathrm{wt} . \%$ of PSN, which resulted in a lower apparent energy of activation. With the increase in heating rate, the activation energy decreases for virgin polymers, while remaining constant for blends, indicating a plateau. This shows that there is no need to alter the design for thermal or thermo-chemical units to fit any type of biodegradable blend, particularly in the case of PSN. The reaction order for virgin 
LLDPE was also estimated at 1 and at 1 and 2, respectively, for both blends. It was also observed that, by the regression coefficients for all heating rates, the theoretical data were in close proximity to the experimental data points. In addition, it was notable that, with the increase in the PSN fraction in blends, the TG curve showed a shift to a lower value in the degradation temperature. The results also clearly depicted the loss of moisture in the first stages, due to water absorption from the atmosphere by the starch content in the polymeric blend.

\section{REFERENCES}

[1] Amin, R.M., Sreekumar, P.A., Al-Harthi, M.A., De, S.K. \& Abu-Sharkh, B.F., Natural weather ageing of the low-density polyethylene: Effect of Polystarch N. Journal of Applied Polymer Science, 127(2), pp. 1122-1127, 2013.

[2] Scott, G., Environmental Biodegradation of Hydrocarbon Polymers: Initiation and Control. Biodegradable Plastic and Polymers, eds Doi, Y. \& Fukuda, K., Elsevier: Amsterdam, pp. 79-91, 1994.

[3] Al-Salem, S.M., Influence of natural and accelerated weathering on various formulations of linear low density polyethylene (LLDPE) films. Materials \& Design, 30(5), pp. 1729-1736, 2009.

[4] El-Naggar, M.M.A. \& Magdy, G.F., Physical and biological treatments of polyethylene-rice starch plastic films. Journal of Hazardous Materials, 176, pp. 878-883, 2010.

[5] Zheng, Y., Yanful, E.K. \& Bassi, A.S., A review of plastic waste biodegradation. Critical Reviews in Biotechnology, 25, pp. 243-250, 2005.

[6] Berruezo, M., Luduena, L.N., Rodriguez, E. \& Alvarez, V.A., Preparation and characterization of polystyrene/starch blends for packaging applications. Journal of Plastic Film \& Sheeting, 30(2), pp. 141-161, 2014.

[7] Ruhul, A.M., Abu-Sharkh, B.F. \& Al-Harthi, M., Surface microstructure study of polyethylene blends for developing environmental degradable plastic bags. Journal of Chemical Engineering, 72, pp. 8-11, 2012.

[8] Arutchelvi, J., Sudhakar, M., Arkatkar, A., Doble, M., Bhaduri, S. \& Uppara, P.V., Biodegradation of polyethylene and polypropylene. Indian Journal of Biotechnology, 7, pp. 9-22, 2008.

[9] Homkhiewa, C., Ratanawilaia, T. \& Thongruang, W., Effects of natural weathering on the properties of recycled polypropylene composites reinforced with rubber wood flour. Industrial Crops and Products, 56 pp. 52-59, 2014.

[10] Al-Salem, S.M. \& Khan, A.R., One degradation kinetics of poly (ethylene terephthalate) (PET)/poly(methyl methacrylate) (PMMA) blends in dynamic thermogravimetry. Polymer Degradation \& Stability, 104, pp. 28-32, 2014. 